\title{
Body cell mass index in children: interpretation of total body potassium results
}

\author{
Alexia J. Murphy* and Peter S. W. Davies \\ Children's Nutrition Research Centre, Discipline of Paediatrics and Child Health, Royal Children's Hospital, \\ University of Queensland, Herston, Queensland 4029, Australia
}

(Received 20 August 2007 - Revised 12 November 2007 - Accepted 4 December 2007 - First published online 15 January 2008)

Body cell mass $(\mathrm{BCM})$ is a valuable measure of functional nutritional status in children. As BCM is related to body size, it is essential that BCM is adjusted for stature when interpreting BCM data in children. Our aim was to examine the relationship between height and BCM in healthy children to determine the power by which height should be raised to adjust $\mathrm{BCM}$ for stature. This cross-sectional study calculated $\mathrm{BCM}$ by ${ }^{40} \mathrm{~K}$ counting in 146 healthy children aged between 5 and 18 years. The relationship between BCM and height was explored using $\log -\log$ regression. The present results demonstrate that the power by which height should be raised to adjust for BCM in females is 2.39 (SE 0.09) and for males is 2.92 (SE 0.10). A simplified sex-specific version of the index, $\mathrm{BCM} /$ height $^{2.5}$ for females and $\mathrm{BCM} / \mathrm{height}^{3}$ for males, was found to be statistically valid and numerically convenient, with the proportion of variation that could be attributed to height being less than $2 \%$. The present study shows that there is a difference in the relationship between height and $\mathrm{BCM}$ for males and females and that BCM can be adjusted in children using the $\mathrm{BCM}$ index of $\mathrm{BCM} / \mathrm{height}^{2 \cdot 5}$ for females and $\mathrm{BCM} /$ height $^{3}$ for males.

Body cell mass: Total body potassium: Body composition: Children

The reporting of body composition data in children requires the variability in body size during this rapid period of growth to be taken into consideration. Normalising body composition measurements for body size is one adjustment that is essential if results are to be meaningful in children. The importance of adjusting body components for height (HT) has been previously investigated in children, with fat mass (FM) and fat-free mass (FFM) being adjusted for $\mathrm{HT}^{(1)}$. Studies have found that by raising HT to the power of 2 in both adults and children when adjusting FM and FFM the influence of body size can be minimised ${ }^{(1,2)}$. The adjustment for HT needs to be considered for expressions of all body compartments such as body cell mass (BCM), which is subtly different from FFM.

$\mathrm{BCM}$ is the metabolically active component of the FFM, which contains the energy-metabolising and work-performing tissue $^{(3)}$. The BCM is an ideal indicator of nutritional status, as it is the part of the body which is vital for function, with malnutrition being defined as a loss of functional cell mass. BCM estimation by total body $\mathrm{K}$ (TBK) counting can be used in health and disease, because the $\mathrm{K}$ concentrations in the $\mathrm{BCM}$ are extremely constant and kept within strict limits by homeostatic mechanisms ${ }^{(4)}$. Unlike measurements of FFM, measurements of $\mathrm{BCM}$ are a better reflection of nutritional status in children and those with clinical conditions because they are independent of FFM hydration changes that occur with growth and disease ${ }^{(5-7)}$. For example, in children who are obese, there has been shown to be an increase in the hydration of the FFM, which would induce error in calculating FFM from many methods ${ }^{(7)}$.

As with FM and FFM, it is important that BCM data are adjusted for body size. The amount of BCM is related to HT, with BCM increasing with growth in HT, regardless of improving nutritional status. Not only is it important to adjust BCM for HT when comparing nutritional status between individuals or populations of different heights, but a HT adjustment will also be essential when longitudinally monitoring children, who may grow in HT over the duration of nutritional intervention. It has been shown that as with FM and FFM, the BCM can be adjusted for size by dividing by $\mathrm{HT}^{2}$ in both normal-weight and malnourished women ${ }^{(8)}$. The ideal body size adjustment for BCM in children is yet to be established.

The purpose of the present study was therefore to examine the relationship between $\mathrm{HT}$ and BCM in healthy children, and to determine the power by which HT should be raised to adjust $\mathrm{BCM}$ for stature when examining nutritional status in children.

\section{Material and methods}

\section{Subjects}

The study sample was 146 healthy Caucasian children between the ages of 5 and 18 years who were controls in a

Abbreviations: BCM, body cell mass; BCMI, body cell mass index; FFM, fat-free mass; FM, fat mass; HT, height; $\operatorname{lnBCM}, \log$ of body cell mass; lnHT, log of height; TBK, total body K.

*Corresponding author: Dr Alexia J. Murphy, fax +61 73346 4684, email alexia.murphy@uq.edu.au 
study or recruited as part of a normative study. Subjects were recruited from schools, workplace newsletters and sporting groups. The study protocol was approved by the Royal Children's Hospital Ethics Committee. Written consent was obtained from all parents and the children over age 12 years, while verbal assent was obtained for children under age 12 years.

\section{Measurements}

All measurements were taken in the Body Composition Laboratory at the Royal Children's Hospital. Body weight was measured to the nearest $0.05 \mathrm{~kg}$ using calibrated digital scales (Tanita BWB-600; Wedderburn Scales, Brisbane, Qld, Australia) and HT was measured to the nearest $0.1 \mathrm{~cm}$ using a wall-mounted stadiometer (Holtain Instruments Ltd, Crymych, Dyfed, UK). BMI was calculated as weight divided by HT squared and BMI $Z$-scores were calculated using the LMS values published by the 2000 Centers for Disease Control and Prevention LMS values ${ }^{(9)}$.

As $98 \%$ of TBK is located in the BCM, BCM can be estimated from a known TBK. TBK analysis was performed using a shadow shield whole-body counter (Accuscan, Canberra Industries, Boston, MA, USA), which contains three sodium iodide crystal scintillation detectors arranged above a scanning bed. The crystals detect the $1.46 \mathrm{MeV} \gamma$ rays emitted by the ${ }^{40} \mathrm{~K}$ in the body. A fixed proportion of the body's $\mathrm{K}$ occurs as the natural isotope ${ }^{40} \mathrm{~K}$; thus $\mathrm{TBK}$ can be determined from the ${ }^{40} \mathrm{~K}$ scan.

The measurement of a subject's TBK required the subject to lie supine on a bed that is moved under the detectors. Two $1067 \mathrm{~s}$ scans were performed for each subject to check reproducibility. Background and sensitivity checks were considered in each measurement, with TBK reported in grams. BCM was calculated from TBK using the equation of Wang et al. ${ }^{(10)}$ :

$$
\mathrm{BCM}(\mathrm{kg})=(\mathrm{TBK}(\mathrm{g}) \times 9 \cdot 20) / 39 \cdot 1 .
$$

\section{Statistical analysis}

The relationship between BCM and HT was investigated using $\ln -\ln$ regression analysis. For each sex, the $\ln$ of $\mathrm{BCM}$ $(\ln B C M)$ was regressed on the $\ln$ of HT $(\operatorname{lnHT})$, and the gradient $(p)$ of the regression equation was determined. The index $\mathrm{BCM} / \mathrm{HT}^{p}$ will then have zero correlation with $\mathrm{HT}$, therefore representing a size-independent index of BCM.

A power will be more clinically useful if it is easy to apply, therefore we rounded $p$ to the closest half decimal, ensuring that this value was within the standard error of $p$. To determine the implication of a correlation between BCM and $\mathrm{HT}^{p}$ using this adjustment, the proportion of variation in BCM that could be attributed to HT was calculated. The statistical package Minitab (version 8.21; Minitab, Inc., State College, PA, USA) was used for statistical analysis.

\section{Results}

The final study sample consisted of 146 healthy children (seventy-two females and seventy-four males) between the ages of 5.2 and 17.9 years. The subject characteristics are given in Table 1 . The male and female subjects were similar
Table 1. Characteristics of the study population

(Mean values and standard deviations)

\begin{tabular}{lccccc}
\hline & \multicolumn{2}{c}{ Females $(n 72)$} & & \multicolumn{2}{c}{ Males $(n 74)$} \\
\cline { 2 - 3 } \cline { 6 - 6 } & Mean & SD & & Mean & SD \\
\hline Age (years) & 11.7 & 3.6 & & 11.9 & 3.4 \\
Height $(\mathrm{cm})$ & 146.4 & 19.8 & & 153.1 & 20.5 \\
Weight $(\mathrm{kg})$ & 40.90 & 15.45 & & 46.25 & 17.60 \\
BMI $\left(\mathrm{kg} / \mathrm{m}^{2}\right)$ & 18.2 & 2.9 & & 18.9 & 3.0 \\
BMI Z-score & -0.05 & 0.83 & & 0.18 & 0.78 \\
Total body K $(\mathrm{g})$ & 71 & 23 & & 88 & 35 \\
Body cell mass $(\mathrm{kg})$ & 16.6 & 5.4 & & 20.6 & 8.3 \\
\hline
\end{tabular}

in ages and representative of a healthy paediatric population with BMI $Z$-scores close to zero.

The statistics for the regression of $\ln \mathrm{BCM}$ on $\ln \mathrm{HT}$ are given in Table 2. The regression equation for females was $\ln B C M$ $(\mathrm{kg})=2.354 \ln \mathrm{HT}(\mathrm{m})+1.881$ and for males was $\operatorname{lnBCM}$ $(\mathrm{kg})=2.927 \ln \mathrm{HT}(\mathrm{m})+1.724$. The values of $p$ were 2.35 (SE 0.09) and 2.93 (SE 0.10) for the female and male groups respectively. The closest half decimal to which these $p$ values were rounded was 2.5 for females and 3.0 for males. If the $\mathrm{BCM}$ indices (BCMI) of $\mathrm{BCM} / \mathrm{HT}^{2.5}$ for females and $\mathrm{BCM} /$ $\mathrm{HT}^{3.0}$ for males were applied, then the proportion of variation in these indices that could be attributed to HT was $2 \%$ for females and $1 \%$ for males. The BCMI was plotted against age for males and females in Fig. 1 to demonstrate that effect of stature on BCM was essentially eliminated using the BCMI. The regression equation was $\mathrm{BCMI}=0.033 \mathrm{age}+5.0386$ for males and $\mathrm{BCMI}=-0.0176 \mathrm{age}+6.4554$ for females.

\section{Discussion}

The aim of the present study was to examine the relationship between BCM and HT in healthy children to determine the optimal adjustment of BCM for HT. The study shows that $\mathrm{BCM}$ can be adjusted in children using the BCMI of BCM/ $\mathrm{HT}^{2.5}$ for females and $\mathrm{BCM} / \mathrm{HT}^{3}$ for males. The regression equations for females and males both gave values for $p$ close to 2.5 and 3 , but not equal to this value. By using the numerically convenient and statistically valid HT adjustment of 2.5 for females and 3 for males, the amount of variation that is not accounted for by this adjustment is minimal, being less than $2 \%$. Thus there is no benefit to be gained from using the specific power values determined.

Our findings show that there is a difference between males and females in the relationship between BCM and HT. It is clear from the present study that the same power correction for HT can not be used in males and females and using the same BCMI would introduce significant variation not accounted for in HT of up to $40 \%$. Flynn et al. ${ }^{(11)}$ examined the regression

Table 2. Regression of log of body cell mass on log of height

\begin{tabular}{lcc}
\hline & Females $(n 72)$ & Males $(n 74)$ \\
\hline$p^{*}$ & 2.35 & 2.93 \\
Intercept & 1.88 & 1.72 \\
SE of gradient & 0.09 & 0.10 \\
$95 \% \mathrm{Cl}$ & $2 \cdot 18,2.53$ & $2.73,3.12$ \\
\hline
\end{tabular}

* Gradient of the regression equation. 


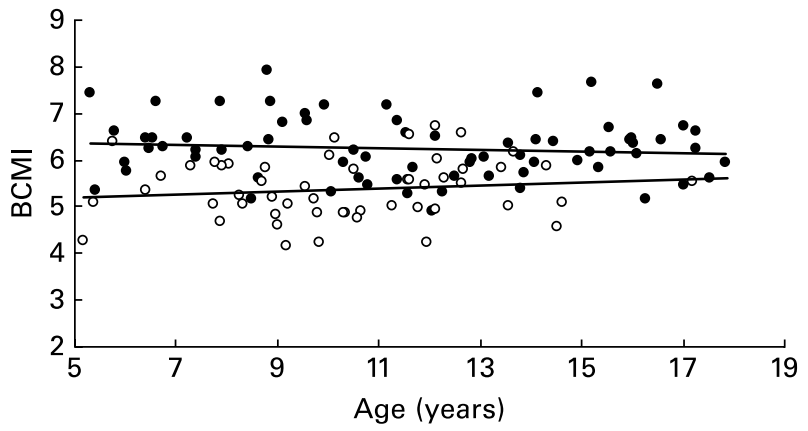

Fig. 1. The body cell mass index (BCMI) of males $(O)$ and females $(\bullet)$ plotted against age. For males, $y=0.033 x+5.0386$; for females, $y=-0.0176 x+6.4554$.

of TBK on HT in 462 children. Their findings support the present result of a sex difference, showing that above $135 \mathrm{~cm}$, about age 10 years, girls have less $\mathrm{K}$ per $\mathrm{cm}$ of HT than boys do. A sex difference is to be expected in the relationship between HT and BCM to account for the variation in composition of weight gain seen during childhood and adolescence.

No other studies, to the best of our knowledge, have examined the adjustment of BCM for HT in children. However, the relationship between $\mathrm{BCM}$ and size has been investigated recently in women of different weights. Wells et al. ${ }^{(8)}$ found that the power adjustment of two was suitable for use in healthy and malnourished women. The HT adjustment of 2 has also been used in previous studies of adults ${ }^{(12,13)}$. From our findings it is evident that the power adjustment of 2 is not suitable for use in children. For both sexes the power of 2 falls beyond the $95 \% \mathrm{CI}$, and if the power of 2 is applied, the proportion of variation not accounted for by HT increases to $21 \%$ for females and $55 \%$ for males.

Previous studies have used these sex-specific BCMI to represent nutritional status in children with cystic fibrosis and those undergoing bone marrow transplant ${ }^{(14,15)}$. The use of these paediatric sex-specific BCMI will allow more accurate analysis of BCM data and expression of nutritional status between groups and individuals of children with different heights, especially those with clinical conditions and healthy controls. The clinical application of the present study's findings will also ensure that BCM will be able to monitor the longitudinal response of children to nutritional support, eliminating the effect of growth in stature.

The present study shows for the first time the normalisation for body size of BCM in children. By using the BCMI for healthy children of $\mathrm{BCM} / \mathrm{HT}^{2.5}$ for females and $\mathrm{BCM} / \mathrm{HT}^{3}$ for males, the effect of stature on BCM can be essentially eliminated. It is vital to adjust body compartment data for stature in children and thus this finding has significant clinical and academic significance for the reporting, monitoring and comparison of BCM data in children.

\section{Acknowledgements}

The authors wish to thank the Royal Children's Hospital Foundation for their financial support of the Children's
Nutrition Research Centre. The authors have no personal, commercial, political, academic or financial conflicts of interest in this research. A. J. M. was responsible for the subject testing, research design and writing of the manuscript. P. S. W. D. conducted the statistical analysis and significantly contributed to the research design, interpretation of results and review of the manuscript.

\section{References}

1. Wells JCK, Cole TJ \& the ALASPAC Team (2002) Adjustment of fat-free mass and fat mass for height in children aged 8 y. Int J Obes 26, 947-952.

2. Van Itallie TB, Yang M, Heymsfield S, Funk RC \& Boileau RA (1990) Height-normalised indices of the body's fat free and fat mass: potentially useful indicators of nutritional status. Am J Clin Nutr 52, 953-959.

3. Moore FD (1980) Energy and the maintenance of the body cell mass. JPEN J Parenter Enteral Nutr 4, 228-260.

4. Edmonds CJ, Jasani BM \& Smith T (1975) Total body potassium and body fat estimation in relationship to height, sex, age, malnutrition and obesity. Clin Sci Mol Med 48, 431-440.

5. Murphy AJ, Wells JCK, Williams JE, Fewtrell MS, Davies PSW \& Webb DK (2006) Body composition in children in remission from acute lymphoblastic leukemia. Am J Clin Nutr 83, 70-74.

6. Wells JCK, Fuller NJ, Dewit O, Fewtrell MS, Elia M \& Cole TJ (1999) Four-component model of body composition in children: density and hydration of fat-free mass and comparison with simpler models. Am J Clin Nutr 69, 904-912.

7. Haroun D, Wells JCK, Williams JE, Fuller NJ, Fewtrell MS \& Lawson MS (2005) Composition of the fat-free mass in obese and nonobese children: matched case-control analyses. Int $J$ Obes 29, 29-36.

8. Wells JCK, Murphy AJ, Buntain HM, Greer RM, Cleghorn GJ \& Davies PSW (2004) Adjusting body cell mass for size in women of differing nutritional status. Am J Clin Nutr 80, 333-336.

9. National Center for Health Statistics (2004) 2000 CDC Growth Charts. Selected Percentiles and LMS Parameters. Hyattsville, MD: National Center for Health Statistics.

10. Wang Z, St-Onge MP, Lecumberri B, et al. (2004) Body cell mass: model development and validation at the cellular level of body composition. Am J Physiol Endocrinol Metab 286, E123-E128.

11. Flynn MA, Woodruff C, Clark J \& Chase G (1972) Total body potassium in normal children. Pediatr Res 6, 239-245.

12. Talluri A, Liedtke RJ, Mohamed EI, Maiolo C, Martinoli R \& De Lorenzo A (2003) The application of body cell mass index for studying muscle mass changes in health and disease. Acta Diabetol 40, S286-S289.

13. Talluri A (1998) Qualitative human body composition analysis assessed with bioelectrical impedance. Coll Antropol 22, 427-432.

14. White M, Murphy AJ, Hastings Y, Shergold J, Young J, Montgomery C, Davies PSW \& Lockwood L (2005) Nutritional status and energy expenditure in children pre-bone-marrowtransplant. Bone Marrow Transplant 35, 775-779.

15. Murphy AJ, Buntain HM, Wainwright CE \& Davies PSW (2006) The nutritional status of children with cystic fibrosis. Br J Nutr 95, 321-324. 